\title{
Rho Kinase Inhibition Enhances Axonal Regeneration in the Injured CNS
}

\author{
Alyson E. Fournier, Bayan T. Takizawa, and Stephen M. Strittmatter \\ Department of Neurology and Section of Neurobiology, Yale University School of Medicine, New Haven, Connecticut 06510
}

Myelin-associated inhibitors limit axonal regeneration in the injured brain and spinal cord. A common target of many neurite outgrowth inhibitors is the Rho family of small GTPases. Activation of Rho and a downstream effector of Rho, p160ROCK, inhibits neurite outgrowth. Here, we demonstrate that Rho is directly activated by the myelin-associated inhibitor Nogo-66. Using a binding assay to measure Rho activity, we detected increased levels of GTP Rho in PC12 and dorsal root ganglion (DRG) cell lysates after Nogo-66 stimulation. Rho activity levels were not affected by Amino-Nogo stimulation. Rho inactivation with C3 transferase promotes neurite outgrowth of chick DRG neurons in vitro, but with the delivery method used here, it fails to promote neurite outgrowth after corticospinal tract (CST) lesions in the adult rat. Inhibition of p160R0CK with Y-27632 also promotes neurite outgrowth on myelin-associated inhibitors in vitro. Furthermore, Y-27632 enhances sprouting of CST fibers in vivo and accelerates locomotor recovery after CST lesions in adult rats.

Key words: Nogo; myelin; axon inhibition; ROCK; Y-27632; C3; regeneration

\section{Introduction}

Neurons in the CNS do not spontaneously regenerate axons after injury. One reason for this abortive regenerative response is the presence of axonal outgrowth inhibitors in the CNS environment. Several inhibitors in myelin have been identified, including myelin-associated glycoprotein (MAG) (McKerracher et al., 1994; Mukhopadhyay et al., 1994; Liu et al., 2002), chondroitin sulfate proteoglycans (Niederost et al., 1999), oligodendrocyte myelin glycoprotein (Wang et al., 2002), and Nogo (Chen et al., 2000; GrandPre et al., 2000; Prinjha et al., 2000). Nogo possesses two inhibitory domains, Nogo-66 and Amino-Nogo, that function by independent mechanisms (Chen et al., 2000; GrandPre et al., 2000; Prinjha et al., 2000; Fournier et al., 2001). Nogo-66 acts in a soluble monomeric form and is a neuron-specific inhibitor, whereas Amino-Nogo must be clustered for activity and is a nonspecific inhibitor of neuronal and non-neuronal cells. A Nogo-66 receptor (NgR) has been identified (Fournier et al., 2001), but the intracellular mechanisms mediating Nogo inhibition have not been delineated.

One common denominator for both neurite outgrowth inhibition and neurite repulsion is actin rearrangements within the growth cone (Luo et al., 1993; Fournier et al., 2000b). Central to the regulation of the actin cytoskeleton in both neuronal and non-neuronal cells is the Rho family of small GTPases (Hall, 1994; Mackay et al., 1995). Rho family members cycle between an inactive GDP-bound form and an active GTP-bound form. Several lines of evidence suggest that manipulating the activity state of Rho GTPases may modulate growth cone collapse and neurite outgrowth inhibition. The introduction of dominant-negative or constitutively active Rac

Received May 6, 2002; revised Sept. 16, 2002; accepted Nov. 21, 2002.

This work was supported by grants from the National Institutes of Health to S.M.S. and by the McKnight Foundation for Neuroscience. S.M.S. is an Investigator of the Patrick and Catherine Weldon Donaghue Medical Research Foundation.

Correspondence should be addressed to Dr. Stephen Strittmatter, Department of Neurology, Yale University School of Medicine, P.0. Box 208018, New Haven, CT 06510. E-mail: stephen.strittmatter@yale.edu. Copyright $\odot 2003$ Society for Neuroscience $\quad 0270-6474 / 03 / 231416-08 \$ 15.00 / 0$ blocks growth cone collapse in response to semaphorin 3A (Jin and Strittmatter, 1997) or myelin (Kuhn et al., 1999), and Rac participates in axonal patterning in vivo (Hakeda-Suzuki et al., 2002; Ng et al., 2002). Rho activation leads to growth cone collapse and neurite inhibition in a variety of cell lines and primary neurons, and these responses can be attenuated by the inactivation of Rho with C3 transferase (Jalink and Moolenaar, 1992; Jalink et al., 1994; Tigyi et al., 1996; Jin and Strittmatter, 1997; Kozma et al., 1997; Hirose et al., 1998; Kranenburg et al., 1999; Lehmann et al., 1999).

Rho family members signal to the actin cytoskeleton through a variety of downstream effector proteins that bind specifically to the active GTP-bound forms of Rho family GTPases. These effector proteins have been used as glutathione $S$-transferase (GST) fusion proteins in pull-down assays to quantify the extent of GTP-bound Rho GTPases in cell lysates (Manser et al., 1994; Bagrodia et al., 1995; Aspenstrom et al., 1996; Kolluri et al., 1996; Reid et al., 1996; Symons et al., 1996). In addition to using Rho family effector proteins as tools to study the activity state of Rho GTPases, these proteins represent potential targets to disrupt inhibitory signaling. Downstream targets of GTP-bound Rho that are of particular interest are the Rho-associated kinase, p160ROCK (Redowicz, 1999) (ROCK-I) and the related kinase ROK-Rho-kinase (ROCK-II). Activation of ROCK-I or ROCK-II enhances phosphorylation of the regulatory myosin light-chain phosphatase (Kimura et al., 1996; Amano et al., 1997). ROCK-I activation is also necessary and sufficient for agonist-induced neurite retraction and cell rounding in neuroblastoma N1E-115 cells (Hirose et al., 1998). The activity of ROCK-I and ROCK-II can be inhibited with the pyridine derivative Y-27632 (Uehata et al., 1997; Ishizaki et al., 2000). Although several protein kinases such as mitogen- and stress-activated protein kinase, mitogenactivated protein kinase-activated protein kinase $1 \mathrm{~b}$, and phosphorylase kinase can be inhibited by Y-27632 at high doses, this drug is a relatively specific ROCK inhibitor at low concentrations (Davies et al., 2000). Treatment of retinal ganglion cells with Y-27632 reduces ephrin-A5-induced growth cone collapse (Wahl 
a

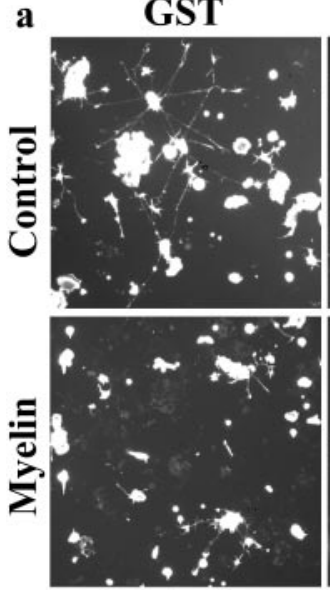

$\mathbf{b}$

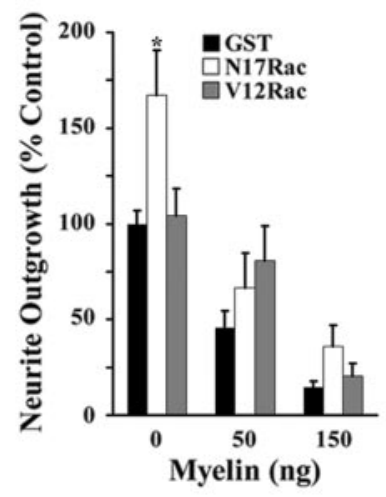

N17Rac

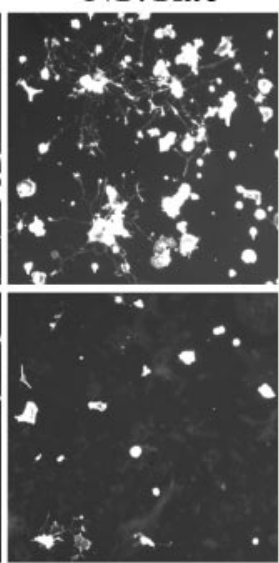

c

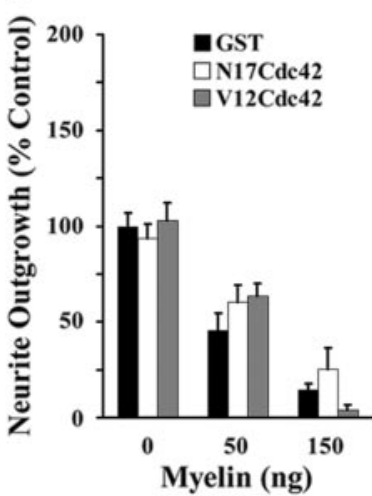

N17Cdc42
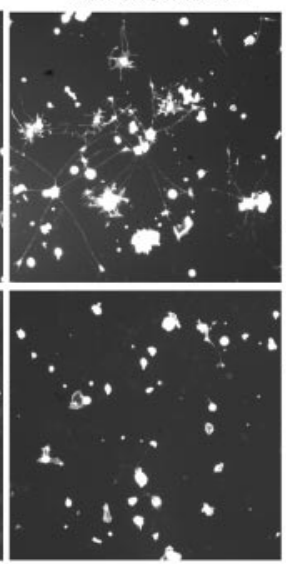

d
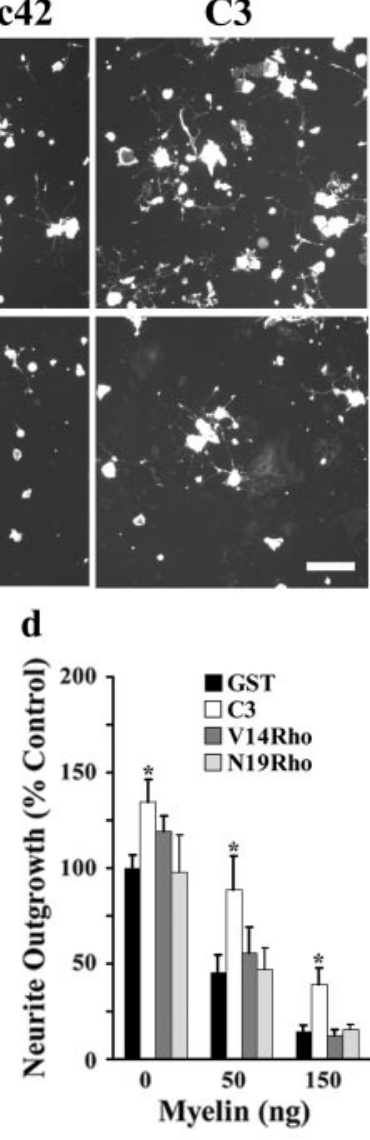

Figure 1. C3 promotes neurite outgrowth on myelin substrates. $a$, Dissociated E13 chick DRG neurons were triturated with dominant-negative or constitutively active Rho GTPases or C 3 and plated on control or myelin spots. $b-d$, Quantification of DRG neurite outgrowth per cell on myelin substrates after trituration with Rho GTPases. Determinations are from 3 to 10 separate experiments. Outgrowth is expressed as a percentage of control \pm SEM. Scale bar, $100 \mu \mathrm{m} .{ }^{*} p<0.01$ compared with GST treatment.

et al., 2000), demonstrating its utility in disrupting liganddependent effects in neurons.

A previous report demonstrated that both $\mathrm{C} 3$ and Y-27632 treatment of mice subjected to corticospinal tract (CST) lesions enhances functional and anatomical recovery (Dergham et al., 2002). To study the effects of Rho family GTPases on outgrowth inhibition, we examined the relationship between the activity state of Rho GTPases and neurite outgrowth on inhibitory substrates. Rho inactivation via C3 transferase promotes dorsal root ganglion (DRG) neurite outgrowth on myelin, MAG, and Nogo-66 substrates. Furthermore, Nogo-66 treatment directly increases GTP-Rho levels in PC12 cells and sensory neurons. However, the application of C3 transferase by a slow-release protocol does not promote longdistance regeneration of rat corticospinal fibers after dorsal hemisection lesions of the spinal cord. ROCK inhibition with Y-27632 promotes DRG outgrowth on inhibitory substrates in vitro and improves the functional and anatomical recovery of rats subjected to spinal cord lesions.

\section{Materials and Methods}

Preparation of recombinant proteins. Dominant-negative (GSTN17Rac, GSTN17Cdc42, and N19RhoA) and constitutively active (GSTV12Rac, GSTV12Cdc42, and GSTV14Rho) fusion proteins and C3 transferase were purified as described previously (Jin and Strittmatter, 1997). Recombinant proteins were eluted with $200 \mathrm{~mm}$ reduced glutathione and were dialyzed against PBS with $10 \mathrm{~mm}$ magnesium. C3 transferase was cleaved with throm-

bin and dialyzed against PBS. GST Nogo-66, Amino-Nogo, and myelin were prepared as described previously (Fournier et al., 2000b; GrandPre et al., 2000). Fc-MAG was generated by ligating residues 19-519 of the soluble ectodomain of MAG inframe with the Fc sequence of the pIG vector as described previously for Fc-L1 (Doherty et al., 1995). Fc-MAG was purified on protein A agarose (Sigma, St. Louis, MO).

Neurite outgrowth assays. Neurite outgrowth and protein trituration experiments were performed as described previously (Jin and Strittmatter, 1997; Fournier et al., 2000a). Briefly, four well chamber slides (Fisher Scientific, Fair Lakes NJ) were coated with $50 \mu \mathrm{g} / \mathrm{ml}$ poly-Llysine (Sigma), and spots of myelin, GST Nogo-66, Fc-MAG, or Amino-Nogo mixed with fluoresbrite plain yellow green $0.5 \mu \mathrm{m}$ microspheres (Polysciences, Inc., Warrington, PA) were dried down on the poly-L-lysine substrate. Slides were then coated with $10 \mu \mathrm{g} / \mathrm{ml}$ laminin (Calbiochem, La Jolla, CA) for $1 \mathrm{hr}$. Embryonic day 13 (E13) chick DRG neurons were dissociated, triturated with C3 or GST fusion proteins, and plated for 3-6 hr. For ROCK inhibition experiments, dissociated neurons were treated with $10 \mu \mathrm{M}$ Y-27632 or PBS for 30 min during the DRG preplating stage and for the entire outgrowth period. Neurons were stained with rhodamine phalloidin (Molecular Probes, Eugene, OR), and neurite outgrowth was quantified using Image J, a public domain JAVA image processing program (http://rsb. info.nih.gov/ij/). For outgrowth quantitation, inhibitory substrates were identified by detecting fluoresbrite microspheres. The total number of cells per inhibitory spot was quantitated. The total neurite length was determined by tracing the length of all neurites on a given spot. The total neurite length was then divided by the total number of cells, yielding a measure of neurite length per cell on each test substrate. Neurite outgrowth per cell was normalized to the average of duplicate control spots for each experiment.

Rho and Rac activity assays. In PC12 cells, Rho or Rac activity assays were performed as described previously (Liu and Burridge, 2000). PC12 cells were differentiated in Roswell Park Memorial Institute 1640 with $1 \%$ fetal bovine serum and $25 \mathrm{ng} / \mathrm{ml}$ nerve growth factor (Calbiochem) for $48 \mathrm{hr}$. After differentiation, cells were treated with $100 \mathrm{~nm} \mathrm{GST-}$ Nogo-66 for $30 \mathrm{~min}$. Cells were rinsed twice with $20 \mathrm{~mm}$ HEPES, pH 7.4, and $150 \mathrm{~mm} \mathrm{NaCl}$ and lysed in supplemented RIPA buffer [20 mM HEPES, $500 \mathrm{~mm} \mathrm{NaCl}, 0.1 \%$ SDS, $0.5 \%$ deoxycholate, $1 \%$ Triton X-100, $10 \mathrm{mM} \mathrm{MgCl}_{2}$, protease inhibitor cocktail (Roche Diagnostics, Mannheim, Germany), $1 \mathrm{~mm}$ phenylmethylsulfonylfluoride, $1 \mathrm{~mm}$ sodium fluoride, and $1 \mathrm{~mm}$ sodium orthovanadate]. GTP-bound Rac was affinityprecipitated from cell lysates (500-1000 $\mu \mathrm{g}$ of protein) using an immobilized GST fusion construct of the Rac1-binding domain of murine p $^{\text {pak }}$ (Bagrodia et al., 1995). GTP Rho was affinity-precipitated using the same procedure with the Rho-binding domain (RBD) of Rhotekin (Ren et al., 1999). Sedimented Rac and Rho were separated using SDS-PAGE, transferred to polyvinylidene difluoride membrane, and blotted with antibodies to Rac (Upstate Biotechnology, Lake Placid, NY), or Rho (Santa Cruz Biotechnology, Santa Cruz, CA).

For GTP Rho pull-down assays from primary sensory neurons, E13 chick DRGs were dissociated and plated on control, Nogo-66, or Amino-Nogo substrates in a six well tissue culture plate. Wells were coated with poly-Llysine and washed, and $330 \mathrm{ng} / \mathrm{cm}^{2}$ Nogo-66, Amino-Nogo, or PBS vehicle was dried down in the well. Wells were washed and coated for $1 \mathrm{hr}$ with 10 $\mu \mathrm{g} / \mathrm{ml}$ laminin as per neurite outgrowth assays (see above). Because of the relatively low levels of Rho in DRG lysates, GTP Rho pull-down assays were 
performed using a Rho activation assay kit (Upstate Biotechnology). GTP Rac levels were assayed as per PC12 cells (see above).

Spinal cord transection and axonal tracing. Adult female Sprague Dawley rats (250-300 gm) were anesthetized with ketamine $(60 \mathrm{mg} / \mathrm{kg})$ and xylazine $(10 \mathrm{mg} / \mathrm{kg})$. Laminectomy was performed at spinal levels T3 and T4, and the spinal cord was exposed. The dorsal half of the spinal cord was cut with a pair of previously marked microscissors to sever the dorsal half of the CST at a depth of $1.5 \mathrm{~mm}$. Histologic examination has revealed that these lesions sever all dorsal CST fibers in the dorsal column and extend past the central canal in all animals. Laterally, the lesions were not as deep, sparing a small proportion of lateral CST fibers. The ventral CST was not injured. An osmotic mini-pump (Alzet 2002; Durect Corp., Cupertino, CA; $200 \mu$ l solution at 0.5 $\mu \mathrm{l}$ per hour over 2 weeks) filled with C3 (11 animals, $300 \mu \mathrm{g}$ per animal over 2 weeks), GST (10 animals, $300 \mu \mathrm{g}$ per animal over 2 weeks), PBS (15 animals, $200 \mu \mathrm{l}$ per animal over 2 weeks), or Y-27632 (12 animals, $340 \mu \mathrm{g}$ per animal over 2 weeks) was sutured to muscles under the skin on the backs of the animals. A catheter connected to the outlet of the minipump was inserted into the intrathecal space of the spinal cord at T4 through a small hole in the dura. Two weeks after the lesion was made, a burr hole was made on each side of the skull overlying the sensorimotor cortex of the lower limbs. The anterograde neuronal tracer BDA (10\% biotin dextran amine in PBS) was applied at seven injection sites at $1,1.5$, and $2 \mathrm{~mm}$ depths from the cortical surface. Each animal received a total of $4 \mu \mathrm{l}$ of BDA. Animals were killed 2 weeks after BDA injection by perfusion with PBS followed by $4 \%$ paraformaldehyde. Cryostat sections of the spinal cord through the lesion were cut parasagittally $(50 \mu \mathrm{m})$. Transverse sections were collected from the spinal cord rostral and caudal to the injury site. Sections were blocked in TBS with $0.5 \%$ BSA for $1 \mathrm{hr}$ and then incubated for $2 \mathrm{~d}$ with avidin-biotin peroxidase (Vector Laboratories, Burlingame, CA) in TBS with $0.15 \%$ BSA. Bound peroxidase was visualized with diaminobenzidine. The sections were mounted on coated slides for analysis.

To quantitate the effects of $\mathrm{C} 3$ on the lesion site, serial sections through the entire width of the spinal cord were analyzed by measuring the area of scar tissue, ventrally spared tissue, and the spinal cord width rostral to the lesion by NIH Image software. By sampling the entire width of each cord, the entire lesion site was analyzed. Scar tissue could be reliably identified by light microscopy.

Behavioral analysis. Animals were given behavioral examinations preoperatively and at $2 \mathrm{~d}$ and 1,2, and 4 weeks after surgery. Animals were assessed according to the Basso-Beattie-Bresnahan (BBB) locomotor rating scale (Basso et al., 1995) to analyze individual components of limb movement, weight support, plantar and dorsal stepping, forelimb-hindlimb coordination, paw rotation, toe clearance, trunk stability, and tail placement. Scores from 0 to 21 were given based on these observations.

\section{Results}

Rho inhibition enhances DRG outgrowth on inhibitory substrates

To examine the effects of Rho, Rac, and Cdc42 activity states on neurite outgrowth, E13 DRG neurons were triturated with dominant-negative (GSTN17Rac, GSTN17Cdc42, and GSTN19Rho) or constitutively active (GSTV12Rac, GSTV12Cdc42, and GSTV14Rho)
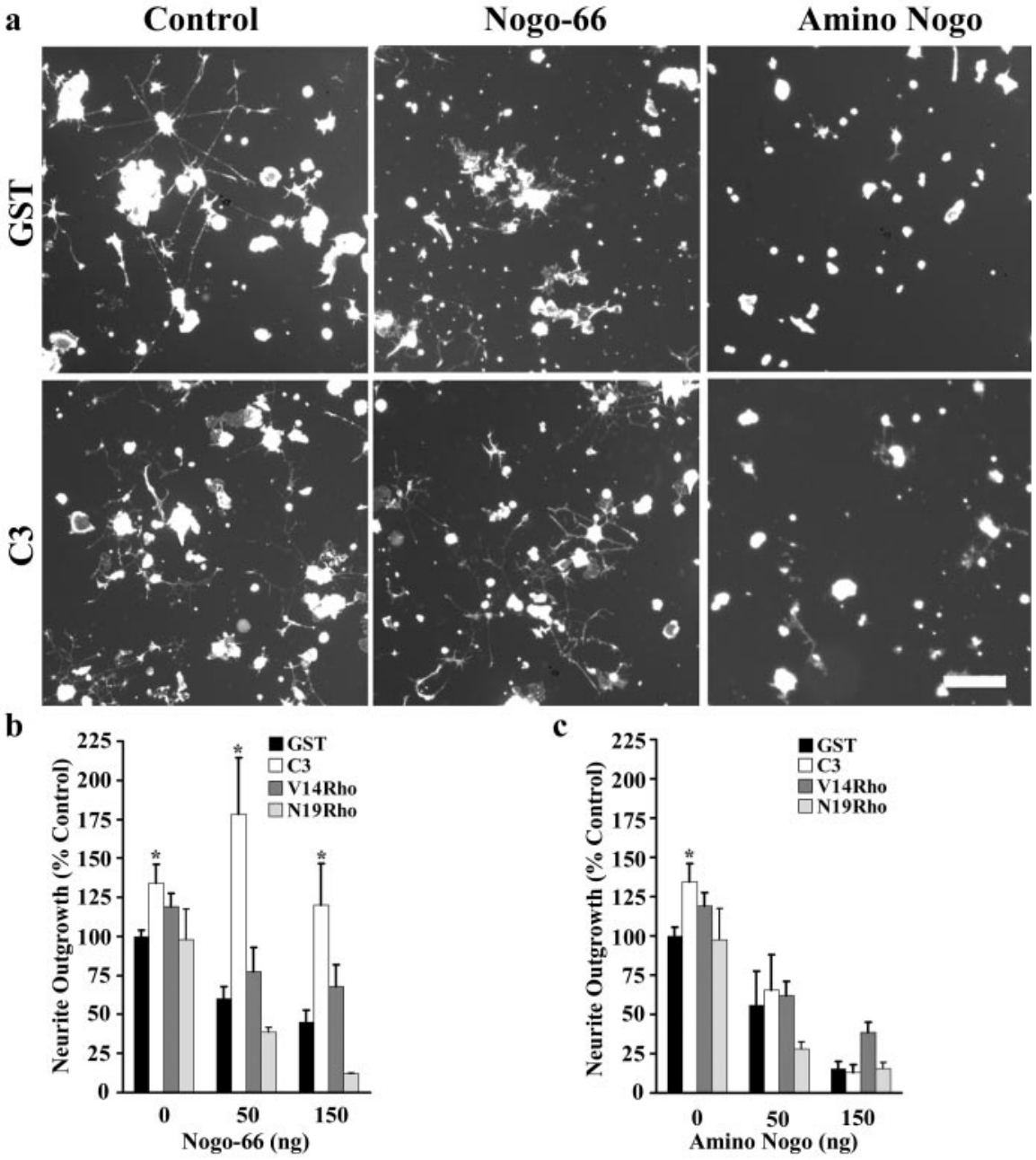

Figure 2. C3 promotes neurite outgrowth on Nogo-66. a, Dissociated E13 chick DRG neurons were triturated with GST control protein, Rho, or C3 transferase and plated on control, GST Nogo-66, or Amino-Nogo spots. C3 treatment promotes outgrowth on Nogo-66 substrates. Outgrowth remains inhibited on high doses of Amino-Nogo. b, c, Quantification of outgrowth from DRG neurons triturated with GST, C3, or Rho proteins. Determinations are from three to six separate experiments. Outgrowth is expressed as a percentage of control \pm SEM. Scale bar, $100 \mu \mathrm{m} .{ }^{*} p<0.01$ compared with GST treatment.

versions of the Rho family GTPases. Rho inactivation was also studied by triturating C3 transferase into DRG neurons. C3 transferase specifically ADP-ribosylates Rho A, B, and C on Asn41, thereby inhibiting its activity without affecting Rac or Cdc42 (Schmidt and Aktories, 1998). Neurite outgrowth was quantitated, expressed as total neurite length per cell, and normalized to the GST control for each experiment. GST control outgrowth on myelin is replotted in Figure $1 b-d$ to better illustrate the effects of recombinant proteins. DRG neurite outgrowth is unaffected by activated or dominant-negative Cdc42 or by activated Rac or Rho (Fig. $1 a-d$ ). The inhibitory response to myelin, GST Nogo-66, Fc-MAG, and Amino-Nogo substrates is also unaffected by these versions of Rho, Rac, and Cdc42 (Figs. 1 and 2, data not shown). In contrast, dominant-negative Rac promotes neurite outgrowth on control substrates but is unable to overcome outgrowth inhibition on myelin, GST Nogo-66, Fc-MAG, or Amino-Nogo substrates (Fig. 1a,b, data not shown).

Similar to dominant-negative Rac, Rho inactivation via C3 transferase has a growth-promoting effect on control substrates and on myelin. This is consistent with previous observations that C3 enhances neuronal outgrowth on MAG and myelin (Jin and Strittmatter, 1997; Lehmann et al., 1999). N19RhoA is ineffective 
at promoting neurite outgrowth on control or inhibitory substrates. This is not surprising, because it has been shown previously that GST N19RhoA is a poor reagent to study Rho inactivation. N19RhoA is mostly insoluble when purified from bacteria (Self and Hall, 1995) and is a relatively weak inhibitor of Rho action (Tashiro et al., 2000). Its ineffectiveness may be a result of poor protein stability (Self and Hall, 1995). To further define the action of C3, its effect on specific myelin inhibitors was examined. C3 treatment promotes outgrowth on GST Nogo-66 but not Amino-Nogo substrates (Fig. 2). Neurite outgrowth on control substrates after C3 or Rho trituration is replotted to better illustrate changes on inhibitory substrates. This confirms the separate modes of Nogo-66 and Amino-Nogo action. The data raise the possibility that Nogo-66 may directly activate Rho to inhibit outgrowth and that C3-mediated blockade of Rho activation prevents inhibitory signaling to the actin cytoskeleton.

\section{Nogo-66 directly activates Rho}

Because C3 also enhances neurite outgrowth on permissive substrates, its participation in Nogo-66 and myelin inhibition might be indirect. To test whether Nogo-66 directly activates Rho, we affinity-precipitated GTP Rho from ligand-treated cells with the RBD of Rhotekin (Ren et al., 1999). PC12 cells, which are known to respond to Nogo-66 (GrandPre et al., 2000), were primed with NGF for $48 \mathrm{hr}$ and treated for $30 \mathrm{~min}$ with $100 \mathrm{~nm}$ GST Nogo-66. Stimulation with GST Nogo-66 enhances GTP Rho levels without modifying total Rho protein levels (Fig. 3a). RhoGTP levels were examined in 15 PC12 cell samples over three separate experiments. Rho activation was stimulated in 11 of 15 samples up to twofold after a $30 \mathrm{~min}$ treatment with GST Nogo-66. RhoGTP levels in the remaining four samples remained unchanged. The RhoGTP levels shown in Figure $3 a$ are representative of the upregulation after a 30 min Nogo-66 treatment. GTP Rac was also affinity-precipitated from treated lysates using the Rac1 binding domain of murine $\mathrm{p} 65^{\mathrm{pak}}$. Rac activity levels are not modified by a 30 min stimulation with GST Nogo-66.

We also examined Rho activation levels in sensory neurons (Fig. $3 b$ ). DRGs were dissociated and plated for $3 \mathrm{hr}$ on control, Nogo-66, or Amino-Nogo substrates. Lysates were collected, and GTP Rho and GTP Rac pull-down assays were performed. GTP Rho levels in cells plated on Nogo-66 substrates were $189 \pm 29 \%$ of GTP Rho levels in control lysates (Fig. 3c). No change in GTP Rho levels was observed in sensory neurons plated on Amino-Nogo substrates. GTP Rac levels remained unchanged in sensory neurons plated on Nogo-66 or Amino-Nogo substrates. Therefore, Nogo-66 specifically stimulates Rho activation, and blockade of such activation with C3 blocks Nogo-dependent inhibition.

\section{C3 disrupts scar formation and delays locomotor recovery after CST lesions}

Because C3 promotes neurite outgrowth on multiple inhibitory substrates in vitro and promotes the regenerative growth of retinal ganglion cells in vivo (Lehmann et al., 1999), we tested its ability to promote the regeneration of CST fibers after dorsal hemisection lesions at thoracic level T3/T4 in adult rats. C3 or GST control protein was delivered via Alzet minipumps with catheters placed intrathecally near the site of thoracic injury. The CST was traced by BDA injection into the motor cortex. After injury, the recovery of locomotor behavior was assessed using the BBB (Basso et al., 1995) scale (Fig. 4a). Animals undergoing a dorsal hemisection at level T3/T4 eventually regain complete functional recovery as assessed by the $\mathrm{BBB}$ scale. C3-treated animals are significantly worse than control animals immediately

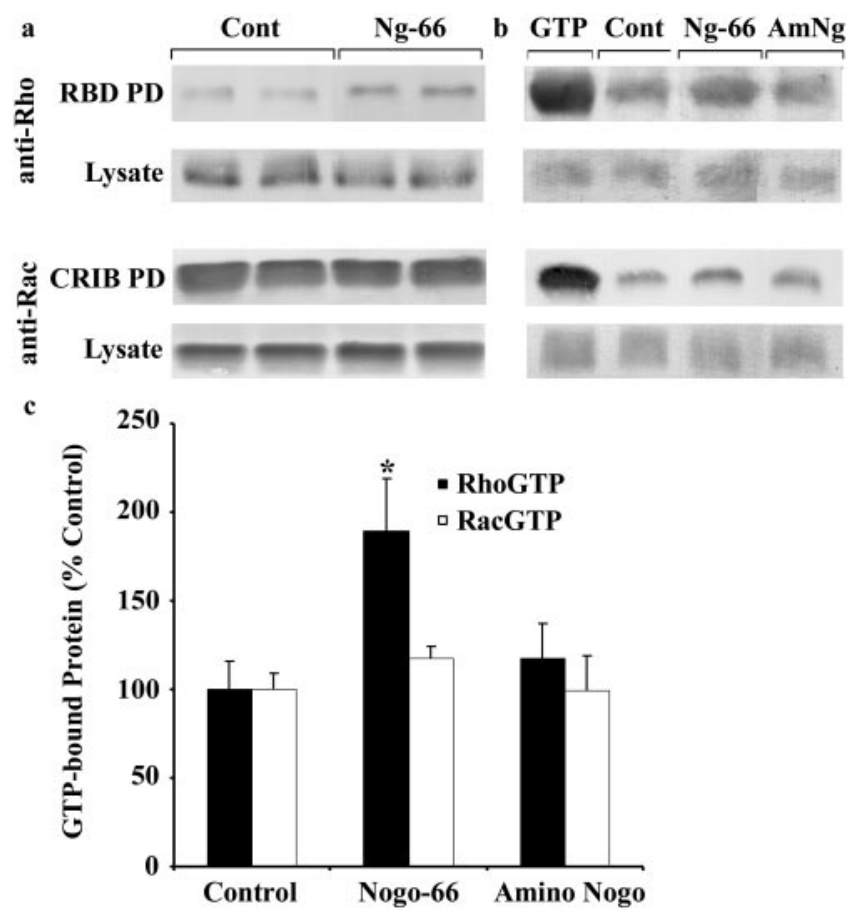

Figure 3. Nogo-66 directly activates Rho. a, PC12 cells were treated for 30 min with $100 \mathrm{~nm}$ GST Nogo-66 (Ng-66), and cell lysates were affinity-precipitated with GST-RBD [RBD pull down $(P D)]$ to detect GTP-bound Rho. GTP Rho levels are enhanced after stimulation with GST Nogo66. Total Rho protein levels remain unchanged in cell lysates. Lysates were also affinityprecipitated with GST-CRIB (Cdc42/Rac1 interacting and binding domain of $\mathrm{p} 65^{\mathrm{pak}}$ to detect activated Rac. Levels of GTP Rac are unaffected by Nogo-66 stimulation. Cont, Control; $b$, E13 chick DRGs were plated on control, Nogo-66 ( $\mathrm{Ng}-66)$, or Amino-Nogo $(\mathrm{AmNg})$ substrates for 3-5 hr. Cell lysates were collected and analyzed for levels of GTP Rho or GTP Rac. Cells plated on Nogo-66 substrates have elevated levels of GTP Rho. As a positive control, cell lysates were incubated for 30 min with GTP $\gamma$ s before the pull-down assay was performed (GTP). C, Quantitation of GTP Rho levels in sensory neurons. GTP Rho levels were normalized to total Rho protein levels in the cell lysate and expressed as a percentage of GTP Rho in control lysates. Determinations are expressed as a percentage of control \pm SEM and are from three experiments, each in duplicate. ${ }^{*} p=0.033$ compared with the control GTP Rho pull-down assay.

and up to 3 weeks after surgery. Examination of the spinal cords of C3-treated animals reveals a marked constriction near the lesion site compared with control animals (Fig. $4 b, c$ ). The spinal cord constriction appears to be attributable to reduced scar tissue at the lesion site. Scar tissue was identified by light microscopy; therefore, we cannot comment on the identity of the nonneuronal cells constituting the scar area. C3 treatment causes a significant decrease in scar tissue formation, whereas the ventrally spared white matter and the spinal cord width rostral to the lesion site are unaffected (Fig. 4b). Below the level of the lesion, a small and equivalent number of fibers are present in C3- and GST-treated animals, but these are confined to the position of the uninjured ventral CST. The inability of C3 to promote longdistance regrowth of lesioned CST fibers in this protocol may be attributable to its poor access to injured neurons in vivo. Preferential inhibition of astrocyte proliferation or migration might account for the reduced scar formation.

\section{ROCK inhibition promotes outgrowth on inhibitory substrates}

If the unsuccessful attempts to promote regrowth with $\mathrm{C} 3$ are attributable to poor access, then blockade of the Rho pathway with a small molecule inhibitor might be more efficacious. We chose to target the downstream effector ROCK because of the 
existence of a selective, low-molecularweight, cell-permeable inhibitor, the pyridine derivative Y-27632 (Uehata et al., 1997). Y-27632 was tested in vitro with dissociated E13 DRG neurons plated on control or inhibitory substrates. Y-27632 dramatically promotes DRG outgrowth on control substrates and on GST Nogo66, Fc-MAG, and myelin substrates (Fig. $5 a-d)$. High doses of Amino-Nogo continue to inhibit DRG neurite outgrowth in the presence of Y-27632 (Fig. 5a,e).

\section{Y-27632 enhances functional and} anatomical recovery after CST lesions To test the effect of ROCK inhibition in vivo, Y-27632 or PBS vehicle was delivered via Alzet minipumps attached to catheters placed intrathecally near the site of thoracic dorsal hemisection injury. The transection site in control and Y-27632 animals is similar, with equal scar formation in the two groups (Fig. $6 a)$. Transverse sections $3-5 \mathrm{~mm}$ rostral to the lesion in Y-27632- and PBS-treated animals demonstrate that the distribution of most CST fibers resembles that of uninjured animals. However, Y-27632-treated animals show an increased number of axonal sprouts in the dorsal gray matter adjacent to the dorsal CST (data not shown). Longitudinal sections across the spinal cord injury reveal the regenerative growth of CST axons in the dorsal gray matter caudal to the injury site in the Y-27632-treated animals (Fig. 6b). There is a significant increase in the number of CST fibers in gray matter 1-4 mm caudal to the injury site (Fig. $6 c$ ). The presence of small numbers of dorsal white matter fibers in control animals reflects the fact that the spinal cord injury spared a fraction of dorsolateral CST axons. Transverse sections 5 $\mathrm{mm}$ caudal to the injury site demonstrate increased numbers of CST fibers in both dorsal gray and white matter of Y-27632treated rats (Fig. $6 d$ ). The number of such fibers is increased fourfold in dorsal gray matter and twofold in dorsal white matter (Fig. 6e).

Locomotor activity in Y-27632-treated rats is similar to controls immediately after injury; however, recovery is accelerated by Y-27632 application. Locomotor activity is improved by three points on the BBB scale $14 \mathrm{~d}$ after injury (Fig. 7). Complete recovery is observed in both PBS and Y-27632-treated animals $30 \mathrm{~d}$ after injury.

\section{Discussion}

By targeting regulators of the actin cytoskeleton to promote neurite outgrowth after CNS injury, it may be possible to overcome the inhibitory influence of multiple inhibitors with a single antagonist. Here, we demonstrate that two reagents capable of perturbing the Rho signaling pathway, the Rho inhibitor C3 transferase and the ROCK inhibitor Y-27632, can promote neurite outgrowth on multiple myelin-associated inhibitory substrates. In vivo, C3 is unable to promote sprouting or long-distance regeneration of injured CST vehicle-treated animals. c

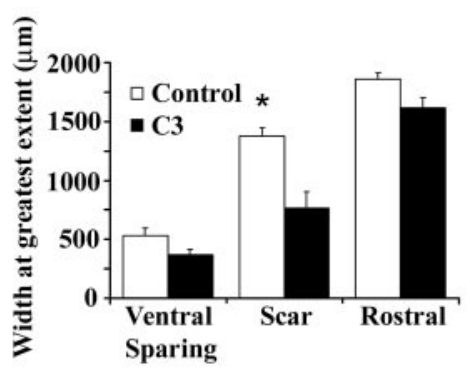

C3
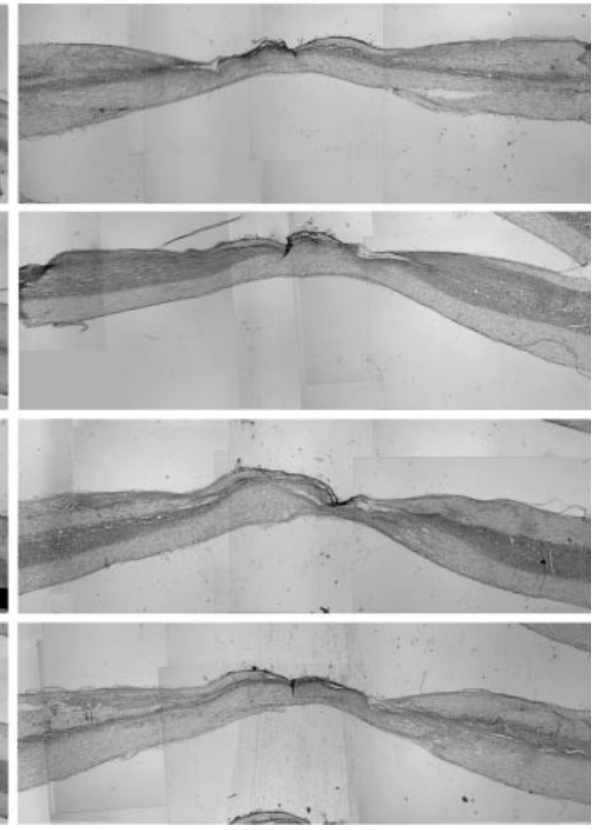

Figure 4. C3 treatment delays locomotor recovery and disrupts scar formation after rat CST lesions. a, Locomotion in C3-treated rats is delayed compared with GST-treated controls. BBB locomotor assessments were made 2, 7, 14, 21, and $28 \mathrm{~d}$ postoperatively. SC, Spinal cord injury. $b$, Longitudinal sections of control and C3-treated spinal cords at the site of transection. Note the obvious cord constriction at the lesion site after (3 treatment relative to control. c, Quantification of scar tissue, ventrally spared tissue

fibers using a slow-release protocol, but Y-27632 treatment enhances both functional and anatomical recovery in adult rats.

The in vitro evidence presented in this paper demonstrating that Rho inactivation promotes the outgrowth of sensory neurons on control and myelin substrates is consistent with results published previously (Lehmann et al., 1999; Dergham et al., 2002), demonstrating that the outgrowth of PC12 cells, retinal neurons, and cortical neurons were enhanced on myelin when cells were scrapeloaded with C3 transferase. However, the results differ from experiments demonstrating that the adenoviral-mediated expression of active Rac or active Rho protects chick motor neurons from CNS myelin inhibition in both growth cone collapse and neurite outgrowth assays (Kuhn et al., 1999). It is unlikely that differences in the neuronal cell type account for these differences. One major difference in the studies is the length of the assay. The results presented in this study assay the outgrowth of cells growing on inhibitory substrates for 3-6 hr. The time course is dictated by the limited half-life of the triturated protein. Kuhn et al. (1999) infected neurons over longer terms using adenovirus and assayed neurite length 3-4 d after 


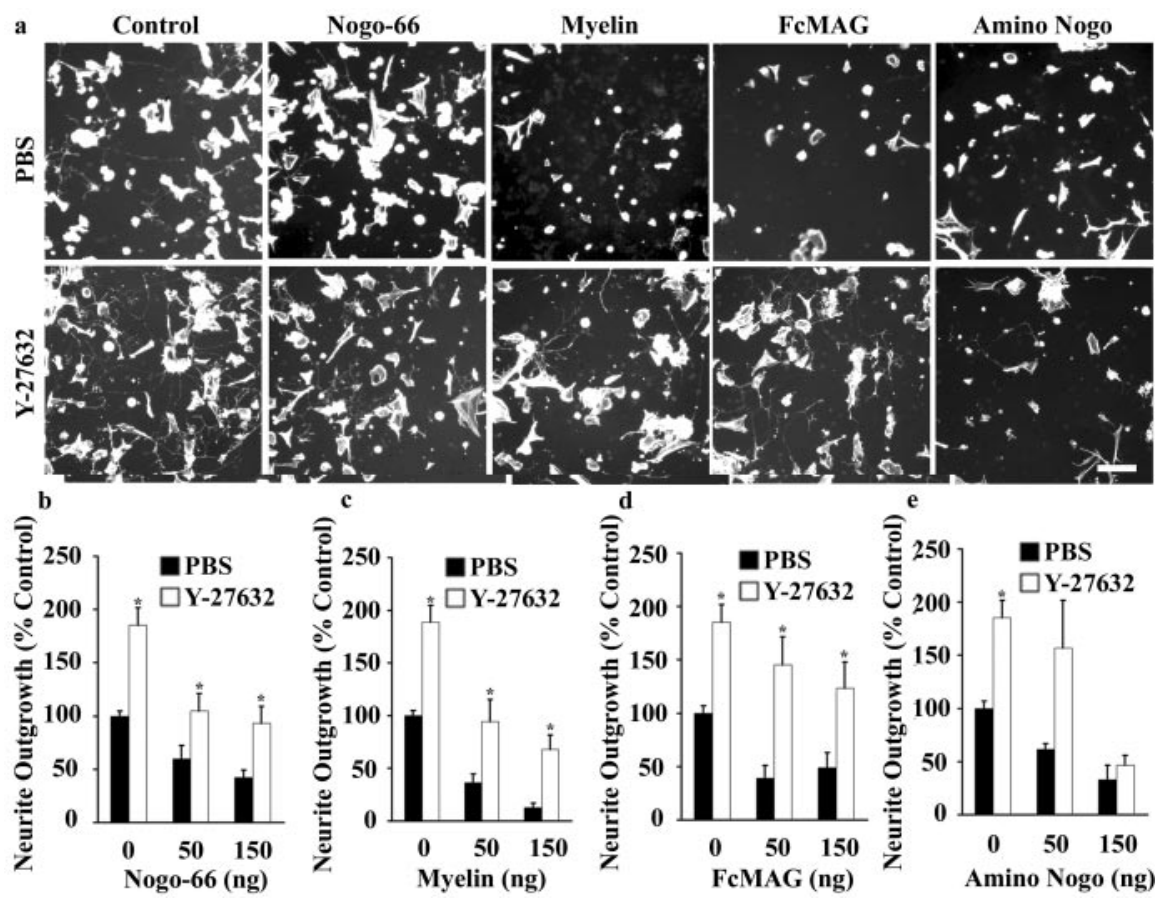

Figure 5. Y-27632 promotes neurite outgrowth on inhibitory substrates. $a$, Dissociated E13 chick DRG neurons were treated with PBS or $10 \mu \mathrm{M}$ Y-27632 and plated on control, GST Nogo-66, myelin, Fc-MAG, or Amino-Nogo spots. Neurite outgrowth is enhanced on control and inhibitory substrates. Y-27632 does not attenuate the inhibition on high doses of Amino-Nogo. $b-e$, Quantification of DRG neurite outgrowth on inhibitory substrates in the presence of PBS or Y-27632. Determinations are from 3 to 10 separate experiments. Outgrowth is expressed as a percentage of control \pm SEM. Scale bar, $100 \mu \mathrm{m} .{ }^{*} p<0.01$ compared with PBS treatment.

plating on myelin substrates. Long-term activation of the Rho family proteins may have secondary effects on protein expression or activity within the neuron. It is also conceivable that myelin proteins are not stable over $3 \mathrm{~d}$ in culture, presenting a modified myelin substrate.

In addition to the ability of C3-induced Rho inactivation to circumvent Nogo-66 inhibition, we also demonstrate that GTP Rho levels are enhanced by Nogo-66 stimulation. Amino-Nogo failed to activate Rho in DRG neurons. Previous studies have demonstrated that the inhibitory effects of Amino-Nogo are more widespread than those of Nogo-66. Furthermore, Amino-Nogo is most active when clustered, whereas Nogo-66 is active as a soluble monomeric ligand (Fournier et al., 2001). The differential effects of Amino-Nogo and Nogo-66 on Rho activation support the contention that the two Nogo domains function by independent mechanisms. This is also consistent with the inability of $\mathrm{C} 3$ to promote neurite outgrowth on Amino-Nogo substrates.

The observation that the introduction of V12Rho alone does not inhibit neurite outgrowth (Fig. 1) suggests that Rho activation is necessary but not sufficient for outgrowth inhibition. We propose a model whereby Nogo binding to Nogo receptor initiates a cascade of signals converging on the actin cytoskeleton and causing outgrowth inhibition. This cascade may be blocked by dominant-negative Rho. A similar mechanism has been reported to explain the effects of V14Rho and C3 on cell spreading and scattering in response to scatter factor (SF)/hepatocyte growth factor (HGF) in Madin-Darby canine kidney cells (Ridley et al., 1995). In this case, microinjection of V14RhoA completely inhibited the spreading response to SF/HGF; however, C3injected cell colonies did not induce SF/HGF-like cell spreading or motility responses. Ridley et al. (1995) present a model in which activated Rho can inhibit cell spreading by blocking upstream spreading signals from Ras and Rac. The inhibitory sig- naling cascade leading from $\mathrm{NgR}$ to the actin cytoskeleton is poorly defined. Because in many ways Rho blockade and ROCK inhibition produce similar effects, ROCK and its target myosin light-chain phosphatase might be considered the presumptive downstream effectors of this pathway. Other downstream effectors of GTP Rho include protein kinase N (PKN) [protein kinase C-related protein kinase (PRK)1/2], citron, citron kinase, mDia1, mDia2, Rhophilin, and Rhotekin (Leung et al., 1995; Ishizaki et al., 1996; Matsui et al., 1996; Nakagawa et al., 1996; Van Aelst and D'Souza-Schorey, 1997; Hall, 1998; Kaibuchi et al., 1999). Several of these effectors are expressed in the brain and may represent additional targets to disrupt neurite outgrowth inhibition.

The in vivo data presented here demonstrate that C3 does not promote sprouting or long-distance regeneration of injured CST fibers after spinal cord lesions in the adult rat. These results differ from those of Dergham et al. (2002) demonstrating long-distance regeneration of anterogradely labeled corticospinal axons in mice. Aside from species and injury differences, the manner of $\mathrm{C} 3$ application may contribute to the differences in the two studies. In this study, C3 was delivered via an Alzet minipump delivering $0.75 \mu \mathrm{g}$ of C3 per hour over 3 weeks (see Materials and Methods). In the study by Dergham et al. (2002), $50 \mu \mathrm{g}$ of C3 was applied to the injury site in a fibrinogen solution immediately after the spinal cord lesion. Dergham et al. (2002) reported immediate improvements for C3-treated animals on the BBB scale as early as $1 \mathrm{~d}$ after lesion. This is presumably attributable to a neuroprotective effect of the massive initial dose of $\mathrm{C} 3$. It is also likely that the large dose of C3 improved its uptake by the distal tip of lesioned CST fibers. In our study, the relatively low amount of C3 introduced at the lesion site at the time of injury likely fails to elicit a neuroprotective effect, and C3 introduced over the 2 weeks after injury may have poor access to distal axon tips. The relative contribution of the neuroprotective effect of C3 and of long-distance axonal regeneration to functional recovery is unclear. Use of cell-permeable C3-like proteins (Winton et al., 2002) and a slow release protocol in vivo would help to define the contribution of these cellular responses.

In this study, we report that Y-27632 promotes neurite outgrowth both in vitro and in vivo. The effects of Y-27632 are likely attributable to its inactivation of ROCK-II, because ROCK-II mRNA is expressed abundantly in the brain, muscle, heart, lung, and placenta. In contrast, ROCK-I mRNA is expressed in multiple tissues other than the brain and muscle (Nakagawa et al., 1996). The relative efficacy of Y-27632 in accelerating regeneration compared with C3 may be attributed to its cell-permeable nature. However, Y-27632 also inhibits PRK2, a protein kinase C-related protein kinase (Flynn et al., 2000), with a potency similar to that for ROCK-II (Davies et al., 2000). PRK 2 is a member of a subfamily of serine-threonine-specific kinases that are downstream effectors of Rho (Amano et al., 1996; Watanabe et al., 1996). PRKs may play a role in the regulation of the cytoskeleton, because fibroblast actin stress fibers are disrupted by 
the expression of a catalytically inactive PRK2, and because PRK1 interacts with the head domain of the intermediate filament subunits (Vincent and Settleman, 1997). The Y-27632 data do not distinguish the relative importance of PRK and ROCK-II in axon outgrowth inhibition.

Rho GTPase and its downstream effectors represent useful targets to overcome neurite outgrowth inhibition. Targeting the Rho pathway offers the advantage of antagonizing multiple myelin-derived inhibitors. Development of more potent and selective antagonists of this pathway may present a viable treatment for spinal cord injury.

\section{References}

Amano M, Mukai H, Ono Y, Chihara K, Matsui T, Hamajima Y, Okawa K, Iwamatsu A, Kaibuchi K (1996) Identification of a putative target for Rho as the serine-threonine kinase protein kinase N. Science 271:648-650.

Amano M, Chihara K, Kimura K, Fukata Y, Nakamura N, Matsuura Y, Kaibuchi K (1997) Formation of actin stress fibers and focal adhesions enhanced by Rho-kinase. Science 275:1308-1311.

Aspenstrom P, Lindberg U, Hall A (1996) Two GTPases, Cdc42 and Rac, bind directly to a protein implicated in the immunodeficiency disorder Wiskott-Aldrich syndrome. Curr Biol 6:70-75.

Bagrodia S, Taylor SJ, Creasy CL, Chernoff J, Cerione RA (1995) Identification of a mouse p21Cdc42/Rac activated kinase. J Biol Chem 270:22731-22737.

Basso DM, Beattie MS, Bresnahan JC (1995) A sensitive and reliable locomotor rating scale for open field testing in rats. J Neurotrauma 12:1-21.

Chen MS, Huber AB, van der Haar ME, Frank M, Schnell L, Spillmann AA, Christ F, Schwab ME (2000) Nogo-A is a myelin-associated neurite outgrowth inhibitor and an antigen for monoclonal antibody IN-1. Nature 403:434-439.

Davies SP, Reddy H, Caivano M, Cohen P (2000) Specificity and mechanism of action of some commonly used protein kinase inhibitors. Biochem J 351:95-105. a
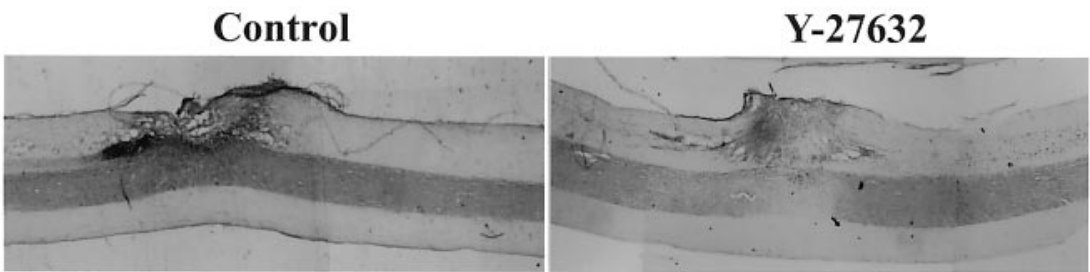

b

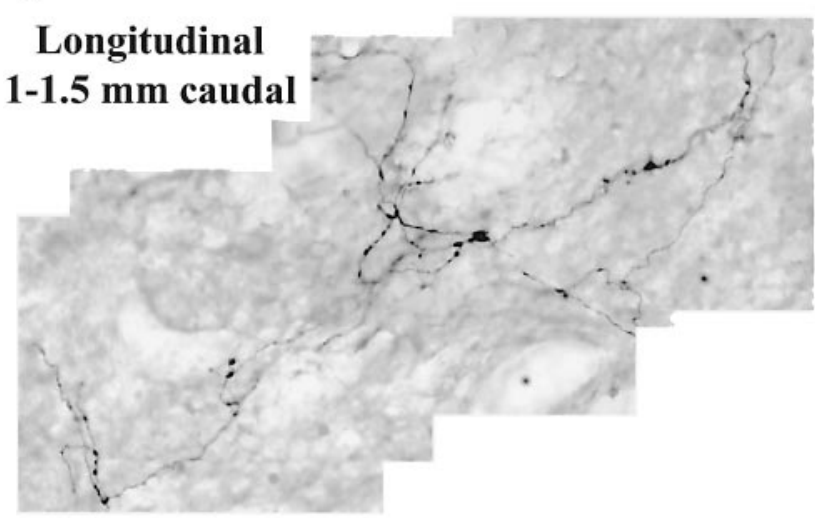

d

\section{Transverse} 5 mm caudal

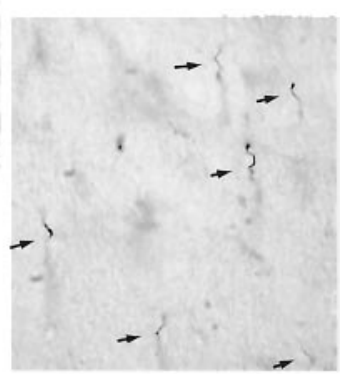

c

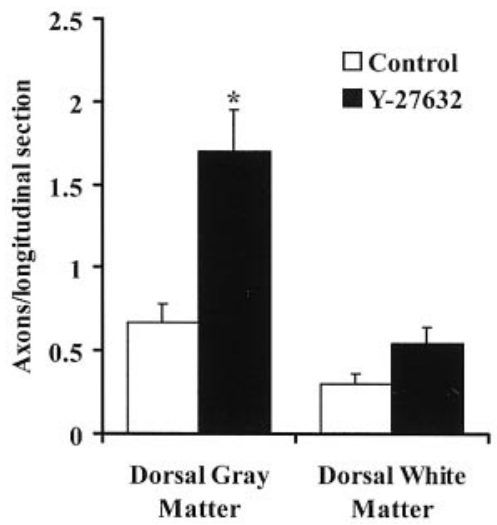

e

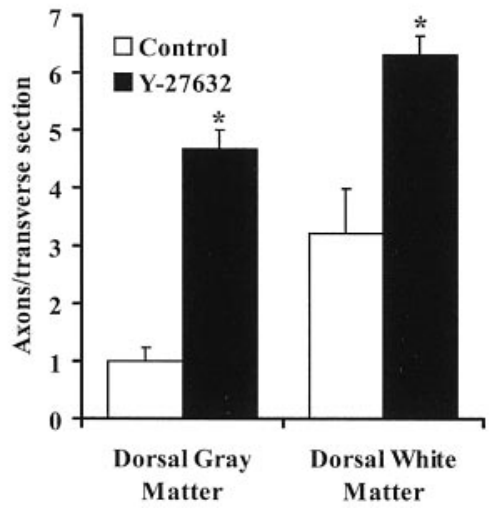

Figure 6. Y-27632 enhances sprouting of rat CST fibers after dorsal hemisections. $a$, Longitudinal sections of control and Y-27632-treated spinal cords at the site of transection. The amount of scar tissue, ventral sparing, and spinal cord width rostral to the lesion is similar for Y-27632-treated and control spinal cords. b, Peroxidase staining of BDA-labeled fibers in a longitudinal section 1-1.5 mm caudal to the CST lesion. C, Quantification of the number of axons per longitudinal section caudal to the CST lesion. $d$, Peroxidase staining of multiple BDA-labeled fibers (arrows) in a transverse section $5 \mathrm{~mm}$ caudal to the CST lesion. $e$, Quantification of the number of axons per transverse section caudal to the CST lesion. Data are from nine vehicle-treated animals and eight $Y$-27632-treated animals. ${ }^{*} p<0.01$ compared with vehicle-treated animals.

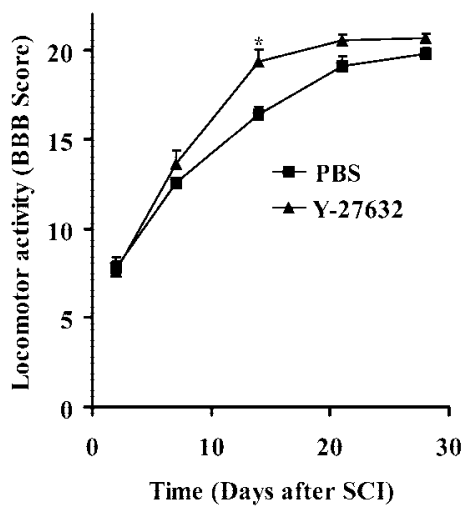

Figure 7. Y-27632 improves locomotor behavior after CST lesions. Rats were evaluated using the BBB score $2,7,14,21$, and 28 d postoperatively. ${ }^{*} p=0.01$. Data are from 15 vehicletreated animals and 12 Y-27632-treated animals. SCI, Spinal cord injury.
Dergham P, Ellezam B, Essagian C, Avedissian H, Lubell WD, McKerracher L (2002) Rho signaling pathway targeted to promote spinal cord repair. J Neurosci 22:6570-6577.

Doherty P, Williams E, Walsh FS (1995) A soluble chimeric form of the L1 glycoprotein stimulates neurite outgrowth. Neuron 14:57-66.

Flynn P, Mellor H, Casamassima A, Parker PJ (2000) Rho GTPase control of protein kinase $\mathrm{C}$-related protein kinase activation by 3 -phosphoinositidedependent protein kinase. J Biol Chem 275:11064-11070.

Fournier AE, Kalb RG, Strittmatter SM (2000a) Rho GTPases and axonal growth cone collapse. Methods Enzymol 325:473-482.

Fournier AE, Nakamura F, Kawamoto S, Goshima Y, Kalb RG, Strittmatter SM (2000b) Semaphorin3A enhances endocytosis at sites of receptor-Factin colocalization during growth cone collapse. J Cell Biol 149:411-422.

Fournier AE, GrandPre T, Strittmatter SM (2001) Identification of a receptor mediating Nogo-66 inhibition of axonal regeneration. Nature 409:341-346.

GrandPre T, Nakamura F, Vartanian T, Strittmatter SM (2000) Identification of the Nogo inhibitor of axon regeneration as a Reticulon protein. Nature 403:439-444.

Hakeda-Suzuki S, Ng J, Tzu J, Dietzl G, Sun Y, Harms M, Nardine T, Luo L, 
Dickson BJ (2002) Rac function and regulation during Drosophila development. Nature 416:438-442.

Hall A (1994) Small GTP-binding proteins and the regulation of the actin cytoskeleton. Annu Rev Cell Biol 10:31-54.

Hall A (1998) Rho GTPases and the actin cytoskeleton. Science 279:509-514

Hirose M, Ishizaki T, Watanabe N, Uehata M, Kranenburg O, Moolenaar WH, Matsumura F, Maekawa M, Bito H, Narumiya S (1998) Molecular dissection of the Rho-associated protein kinase (p160ROCK)-regulated neurite remodeling in neuroblastoma N1E-115 cells. J Cell Biol 141:1625-1636.

Ishizaki T, Maekawa M, Fujisawa K, Okawa K, Iwamatsu A, Fujita A, Watanabe N, Saito Y, Kakizuka A, Morii N, Narumiya S (1996) The small GTP-binding protein Rho binds to and activates a $160 \mathrm{kDa}$ Ser/Thr protein kinase homologous to myotonic dystrophy kinase. EMBO J 15:1885-1893.

Ishizaki T, Uehata M, Tamechika I, Keel J, Nonomura K, Maekawa M, Narumiya S (2000) Pharmacological properties of Y-27632, a specific inhibitor of Rho-associated kinases. Mol Pharmacol 57:976-983.

Jalink K, Moolenaar WH (1992) Thrombin receptor activation causes rapid neural cell rounding and neurite retraction independent of classic second messengers. J Cell Biol 118:411-419.

Jalink K, van Corven EJ, Hengeveld T, Morii N, Narumiya S, Moolenaar WH (1994) Inhibition of lysophosphatidate- and thrombin-induced neurite retraction and neuronal cell rounding by ADP ribosylation of the small GTP-binding protein Rho. J Cell Biol 126:801-810.

Jin Z, Strittmatter SM (1997) Rac1 mediates collapsin-1-induced growth cone collapse. J Neurosci 17:6256-6263.

Kaibuchi K, Kuroda S, Amano M (1999) Regulation of the cytoskeleton and cell adhesion by the Rho family GTPases in mammalian cells. Annu Rev Biochem 68:459-486.

Kimura K, Ito M, Amano M, Chihara K, Fukata Y, Nakafuku M, Yamamori B, Feng J, Nakano T, Okawa K, Iwamatsu A, Kaibuchi K (1996) Regulation of myosin phosphatase by Rho and Rho-associated kinase (Rho-kinase). Science 273:245-248.

Kolluri R, Tolias KF, Carpenter CL, Rosen FS, Kirchhausen T (1996) Direct interaction of the Wiskott-Aldrich syndrome protein with the GTPase Cdc42. Proc Natl Acad Sci USA 93:5615-5618.

Kozma R, Sarner S, Ahmed S, Lim L (1997) Rho family GTPases and neuronal growth cone remodelling: relationship between increased complexity induced by $\mathrm{Cdc} 42 \mathrm{Hs}$, Racl, and acetylcholine and collapse induced by RhoA and lysophosphatidic acid. Mol Cell Biol 17:1201-1211.

Kranenburg O, Poland M, van Horck FP, Drechsel D, Hall A, Moolenaar WH (1999) Activation of RhoA by lysophosphatidic acid and Go12/13 subunits in neuronal cells: induction of neurite retraction. Mol Biol Cell 10:1851-1857.

Kuhn TB, Brown MD, Wilcox CL, Raper JA, Bamburg JR (1999) Myelin and collapsin-1 induce motor neuron growth cone collapse through different pathways: inhibition of collapse by opposing mutants of racl. J Neurosci 19:1965-1975.

Lehmann M, Fournier A, Selles-Navarro I, Dergham P, Sebok A, Leclerc N, Tigyi G, McKerracher L (1999) Inactivation of Rho signaling pathway promotes CNS axon regeneration. J Neurosci 19:7537-7547.

Leung T, Manser E, Tan L, Lim L (1995) A novel serine/threonine kinase binding the Ras-related RhoA GTPase which translocates the kinase to peripheral membranes. J Biol Chem 270:29051-29054.

Liu BP, Burridge K (2000) Vav2 activates Rac1, Cdc42, and RhoA downstream from growth factor receptors but not $\beta 1$ integrins. Mol Cell Biol 20:7160-7169.

Liu BP, Fournier A, GrandPre T, Strittmatter SM (2002) Myelin-associated glycoprotein as a functional ligand for the Nogo-66 receptor. Science 297:1190-1193.

Luo Y, Raible D, Raper JA (1993) Collapsin: a protein in brain that induces the collapse and paralysis of neuronal growth cones. Cell 75:217-227.

Mackay DJ, Nobes CD, Hall A (1995) The Rho's progress: a potential role during neuritogenesis for the Rho family of GTPases. Trends Neurosci 18:496-501.

Manser E, Leung T, Salihuddin H, Zhao ZS, Lim L (1994) A brain serine/ threonine protein kinase activated by $\mathrm{Cdc} 42$ and Racl. Nature $367: 40-46$

Matsui T, Amano M, Yamamoto T, Chihara K, Nakafuku M, Ito M, Nakano
T, Okawa K, Iwamatsu A, Kaibuchi K (1996) Rho-associated kinase, a novel serine/threonine kinase, as a putative target for small GTP binding protein Rho. EMBO J 15:2208-2216.

McKerracher L, David S, Jackson DL, Kottis V, Dunn RJ, Braun PE (1994) Identification of myelin-associated glycoprotein as a major myelinderived inhibitor of neurite growth. Neuron 13:805-811.

Mukhopadhyay G, Doherty P, Walsh FS, Crocker PR, Filbin MT (1994) A novel role for myelin-associated glycoprotein as an inhibitor of axonal regeneration. Neuron 13:757-767.

Nakagawa O, Fujisawa K, Ishizaki T, Saito Y, Nakao K, Narumiya S (1996) ROCK-I and ROCK-II, two isoforms of Rho-associated coiled-coil forming protein serine/threonine kinase in mice. FEBS Lett 392:189-193.

Ng J, Nardine T, Harms M, Tzu J, Goldstein A, Sun Y, Dietzl G, Dickson BJ, Luo L (2002) Rac GTPases control axon growth, guidance, and branching. Nature 416:442-447.

Niederost BP, Zimmermann DR, Schwab ME, Bandtlow CE (1999) Bovine CNS myelin contains neurite growth-inhibitory activity associated with chondroitin sulfate proteoglycans. J Neurosci 19:8979-8989.

Prinjha R, Moore SE, Vinson M, Blake S, Morrow R, Christie G, Michalovich D, Simmons DL, Walsh FS (2000) Inhibitor of neurite outgrowth in humans. Nature 403:383-384.

Redowicz MJ (1999) Rho-associated kinase: involvement in the cytoskeleton regulation. Arch Biochem Biophys 364:122-124.

Reid T, Furuyashiki T, Ishizaki T, Watanabe G, Watanabe N, Fujisawa K, Morii N, Madaule P, Narumiya S (1996) Rhotekin, a new putative target for Rho bearing homology to a serine/threonine kinase, PKN, and Rhophilin in the Rho-binding domain. J Biol Chem 271:13556-13560.

Ren XD, Kiosses WB, Schwartz MA (1999) Regulation of the small GTPbinding protein Rho by cell adhesion and the cytoskeleton. EMBO J 18:578-585.

Ridley AJ, Comoglio PM, Hall A (1995) Regulation of scatter factor/hepatocyte growth factor responses by Ras, Rac, and Rho in MDCK cells. Mo Cell Biol 15:1110-1122.

Schmidt G, Aktories K (1998) Bacterial cytotoxins target Rho GTPases. Naturwissenschaften 85:253-261.

Self AJ, Hall A (1995) Purification of recombinant Rho/Rac/G25K from Escherichia coli. Methods Enzymol 256:3-10.

Symons M, Derry JM, Karlak B, Jiang S, Lemahieu V, McCormick F, Francke U, Abo A (1996) Wiskott-Aldrich syndrome protein, a novel effector for the GTPase $\mathrm{CDC} 42 \mathrm{Hs}$, is implicated in actin polymerization. Cell 84:723-734.

Tashiro A, Minden A, Yuste R (2000) Regulation of dendritic spine morphology by the Rho family of small GTPases: antagonistic roles of Rac and Rho. Cereb Cortex 10:927-938.

Tigyi G, Fischer DJ, Sebok A, Yang C, Dyer DL, Miledi R (1996) Lysophosphatidic acid-induced neurite retraction in PC12 cells: control by phosphoinositide- $\mathrm{Ca}^{2+}$ signaling and Rho. J Neurochem 66:537-548.

Uehata M, Ishizaki T, Satoh H, Ono T, Kawahara T, Morishita T, Tamakawa H, Yamagami K, Inui J, Maekawa M, Narumiya S (1997) Calcium sensitization of smooth muscle mediated by a Rho-associated protein kinase in hypertension. Nature 389:990-994.

Van Aelst L, D'Souza-Schorey C (1997) Rho GTPases and signaling networks. Genes Dev 11:2295-2322.

Vincent S, Settleman J (1997) The PRK2 kinase is a potential effector target of both Rho and Rac GTPases and regulates actin cytoskeletal organization. Mol Cell Biol 17:2247-2256.

Wahl S, Barth H, Ciossek T, Aktories K, Mueller BK (2000) Ephrin-A5 induces collapse of growth cones by activating Rho and Rho kinase. J Cell Biol 149:263-270.

Wang KC, Koprivica V, Kim JA, Sivasankaran R, Guo Y, Neve RL, He Z (2002) Oligodendrocyte-myelin glycoprotein is a Nogo receptor ligand that inhibits neurite outgrowth. Nature 417:941-944.

Watanabe G, Saito Y, Madaule P, Ishizaki T, Fujisawa K, Morii N, Mukai H, Ono Y, Kakizuka A, Narumiya S (1996) Protein kinase N (PKN) and PKN-related protein Rhophilin as targets of small GTPase Rho. Science 271:645-648

Winton MJ, Dubreuil CI, Lasko D, Leclerc N, McKerracher L (2002) Characterization of new cell permeable C3-like proteins that inactivate Rho and stimulate neurite outgrowth on inhibitory substrates. J Biol Chem 277:32820-32829. 